\title{
Electrified lines entering tunnels in Poland, safety aspects of the running with fire
}

\author{
Marek Pawlik ${ }^{1, *}$ \\ ${ }^{1}$ Railway Research Institute, ul. Chłopickiego 50, 04-275, Warsaw, Poland
}

\begin{abstract}
Potential fire on board of the passenger train creates risk for passengers health and passengers life. Using non-flammable materials for producing Electric Multiple Units (EMUs) is not considered to be sufficient as passengers are carrying different types of materials as their luggage and belongings. In case of fire on board of the train, the EMU should stop in a place which is appropriate for passengers evacuation and fire fighting. Not all places along railway lines are considered to be appropriate for such purpose. Especially stopping in tunnels is considered inappropriate. Meanwhile the amount of tunnels on the Polish railway network is growing significantly. This requires application of the Technical Specification for Interoperability regarding Safety in Railway Tunnels (TSI SRT) and set of fire standards EN 45545. Using those requirements is associated with putting tunnels and rolling stock into service under railway interoperability directive 2008/57/WE. Additional analyse is however necessary from operational safety point of view due to growing amount of tunnels and growing diversity of rolling stock. Paper proposes conducting risk analyse in accordance with common safety method for risk evaluation and assessment based on a dedicated European Standard EN 50533 which defines requirements regarding running capability in case of fire on board of the rolling stock. Paper analyses applicability of that approach for group of tunnels and rolling stock fleet comprising different types of rolling stock including Electric Multiple Units.
\end{abstract}

\section{Introduction}

EN 50533 standard [7] distinguishes three types of fire and defines reference fire (with which the train should be able to continue running). It also defines assessment model, which is to be applied for assessing trains and their critical functionalities important for running capability in case of fire. The critical functionalities are especially those ones linked with ensuring appropriate traction and braking necessary for reaching safe place appropriate for passengers evacuation and fire fighting. Quoted standard is generally dedicated for assessment of new trains, as it defines specific technical measures, compliance with which allow the 'presumption of conformity' with Commission Regulation (EU) $1303 / 2014$ [2] concerning technical specification for interoperability relating to 'safety in railway tunnels'.

Despite that, the key challenge in relation to running with fire via tunnels in case of Poland is not to verify new trains, but to verify respective overall safety which is changing due to opening of many tunnels on the Polish railway network taking into account not only new but also existing trains, which are in operation usually longer than twenty years.

\section{Operational safety}

The 10-by-10 safety matrix defined by author in previous publications $[10,11]$ show, that operational safety as well as activities in case of emergency are associated with ten technical safety aspects T1-T10, out of which two, namely $\mathrm{T} 4$ and T9, also have security dimension. The technical aspects which have to be considered are: T1 - malfunctioning safety, T2 construction safety, T3 - electrical safety, T4 preventing unauthorized access and fire, T5 - wheel/rail interaction safety, T6 - control command and signalling (active safety systems), T7 - power supply/signalling interaction safety, T8 - safety of the operational rules and staff competences, T9 - preventing panic, and T10 - IT support for safety. Not all of them are associated with running with fire on the board of the EMU in the context of growing amount of the electrified lines entering tunnels in Poland. However not only T4 which is directly dedicated to fire hazards have to be considered, but also relevant requirements which can be seen as associated with T1, T2, T3, T6, T8 and T9.

\footnotetext{
* Corresponding author: mpawlik@ikolej.pl
} 


\section{Preventing unauthorized access and fire (T4)}

On one side from fire risk point of view it is important to prevent unauthorised access to railway tunnels. This is not directly associated with protection against fire itself, however from the fire hazard point of view it is important to verify that in that respect appropriate measures are defined and applied. On the other side preventing unauthorised access to passenger trains, which are entering tunnels in commercial operation is irrelevant. Passengers can enter trains carrying different types of materials as their luggage and belongings including also flammable materials and products. As unauthorised persons one can point passengers without appropriate tickets, but luggage fire-checks never takes place.

The amount of materials which are carried by passengers is very limited in comparison to materials used for passenger train construction. Taking that into account national railways since many years were defining fire requirements for construction materials. Common approach in that respect was necessary for interoperability purpose since adoption of the interoperability directive [1].

The long and challenging works on common European fire requirements for rolling stock materials resulted finally with EN 45545 standard [5]. This works were conducted with an important and long involvement of Polish experts from Railway Institute (IK) and were disseminated by Institute via publications [8, 9] and organization of the international fire conferences, which take place every second year (e.g. III International Conference on Modern Trends of Fire Protection in Rolling Stock, which took place in Warsaw in 2016). The already agreed standard [5], which sets obligatory requirements for interoperable rolling stock (as it is quoted by European regulation) and non-interoperable rolling stock (as it is quoted by Polish regulation [4]) is still under on-going standardisation works. European Committee for Standardisation (CEN) working parties undertake, together with IK experts, works focused on improving set of seven parts of the EN 45545standard:

- Part 1 - general requirements

- Part 2 - fire behaviour of materials and components

- Part 3 - fire barriers resistance requirements

- Part 4 - fire safety in railway rolling stock design

- Part 5-electrical equipment fire safety

- Part 6 - fire control and management systems

- Part 7 -flammable liquid and gas installations.

Smoke properties, toxicity of combustion products, flame propagation, and flammability are defined taking into account [8]:

- weight of material and dimensions of elements,

- distance from the place of potential ignition, and

- hazard level due to vehicle type \& train category.

Technical Specification for Interoperability regarding 'safety in railway tunnels' (TSI SRT) [2] defines requirements not only for prevention pointing EN 45545 , but also for mitigation, escape and rescue. Those three aspects are associated with ensuring measures which are necessary for activities, which have to be possible in case of emergency.

\section{Risk assessment}

Judgement in relation to mitigation, escape and rescue for new type of rolling stock and for new tunnels is performed on the basis of the TSI SRT [2]. This leads to fully safe situation after modernisation of tunnels and replacement of old rolling stock by new one. This requires however many years and therefore it is proposed to use risk assessment methodology for verifying fire safety for existing and new tunnels as well as existing and new rolling stock.

\subsection{EN 50533 based malfunctioning safety (T1)}

EN 50533 standard is dedicated for verification of running capability in case of fire on board of the train.

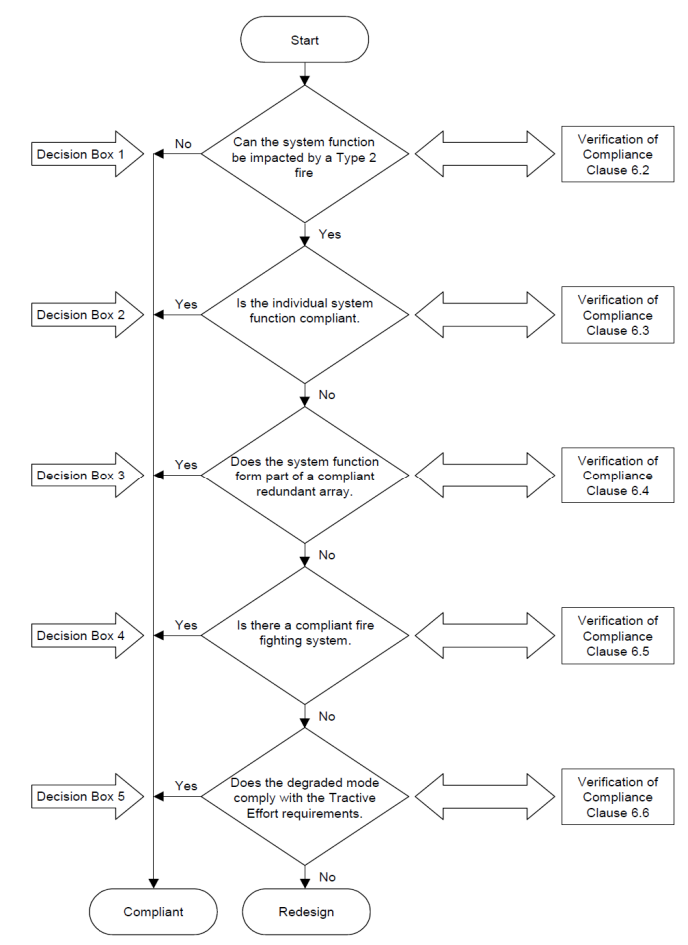

Fig. 1. Decision box approach to running capability. [7]

Figure 1 shows decision box approach defined in EN 50533 Standard for assessing running capability in case of fire on board of rolling stock. Shown algorithm is intended to be used separately for all functionalities, which are identified as critical (especially those ones linked with ensuring appropriate traction and braking necessary for reaching safe place appropriate for passengers evacuation and fire fighting). It is composed by five decision boxes defined in respective chapters of the EN 50533 Standard.

It is important to understand, that these steps are generally performed to prove that all such individual functions would be ensured in case of type 2 fire. The type 2 fire is defined as a "fire which, due to its size 
and/or location, presents a risk of serious injury and/or threat to life and for which it is reasonably practicable to define running capability requirements". Running capability for individual critical functionalities is assessed on the basis of a type 2 reference fire defined as a "fire which has the power vs. time profile of Ignition source 5 of CEN/TS 45545-1; 75kW for 2 minutes followed by $150 \mathrm{~kW}$ for $8 \mathrm{~min}$ ". Three safety measures are foreseen to be used when individual functionality is not compliant itself: moving device performing such functionality to another place in the train, adding second and possibly third device independent from the first one performing the same functionality and located separately to create so called 'redundant array' and adding appropriate fire fighting systems ensuring required running capability.

\subsection{Ensuring control command operation in case of fire and inhibiting passenger break (T6)}

Ensuring correct operation of the control command onboard equipment is an example of functionality which has to be assessed. Fire cannot affect neither performed functions nor fail-safety and SIL 4 safety integrity of respective equipment used for receiving electronic movement authorities and continuous verification of running in compliance with authorities.

Special function is foreseen for new trains and for the European Train Control System ETCS to ensure inhibiting passenger break when as a result of use of such break by passenger train would stop inside the tunnel - in a place inappropriate for evacuation and possibly required fire fitting.

\subsection{Basic hazard log}

All critical identified hazards associated with malfunctioning of critical functionalities, lack of functioning of critical devices associated with critical functionalities as well as loss of fail-safety or SIL4 related functions have to be seen as hazards and put into hazard log. An example hazard log is shown on Figure 2.

Such hazard log prepared in accordance with risk evaluation and assessment regulation [3] is legally required for individual trains, which are being modernized. Application of EN 50533 in case of new types of EMUs and other new types of vehicles can be performed directly according 'decision box' approach.

\subsection{Complementary safety aspects (T2 T3 T8 T9)}

Type 2 fire cannot affect construction safety (T2). Especially it cannot affect within 8 minutes, from the beginning of fire: housings, seals, devices and cables mounting racks, etc.

Type 2 fire cannot affect electrical safety (T3). Especially it cannot cause within 8 minutes neither loos of power supply nor overvoltage. It cannot cause shortcircuits as well as presence of electric arch.

All operational rules (T8) necessary in degraded modes of operation taking place in case of type 2 fire have to be defined and communicated to operational and railway rescue staff. The staff competences and health have to be regularly verified.

All types of equipment foreseen to be used for preventing panic (T9) by e.g. staff communication in emergency and public address systems as well as evacuation ways and doors together with emergency lighting have to be ensured and regularly verified.

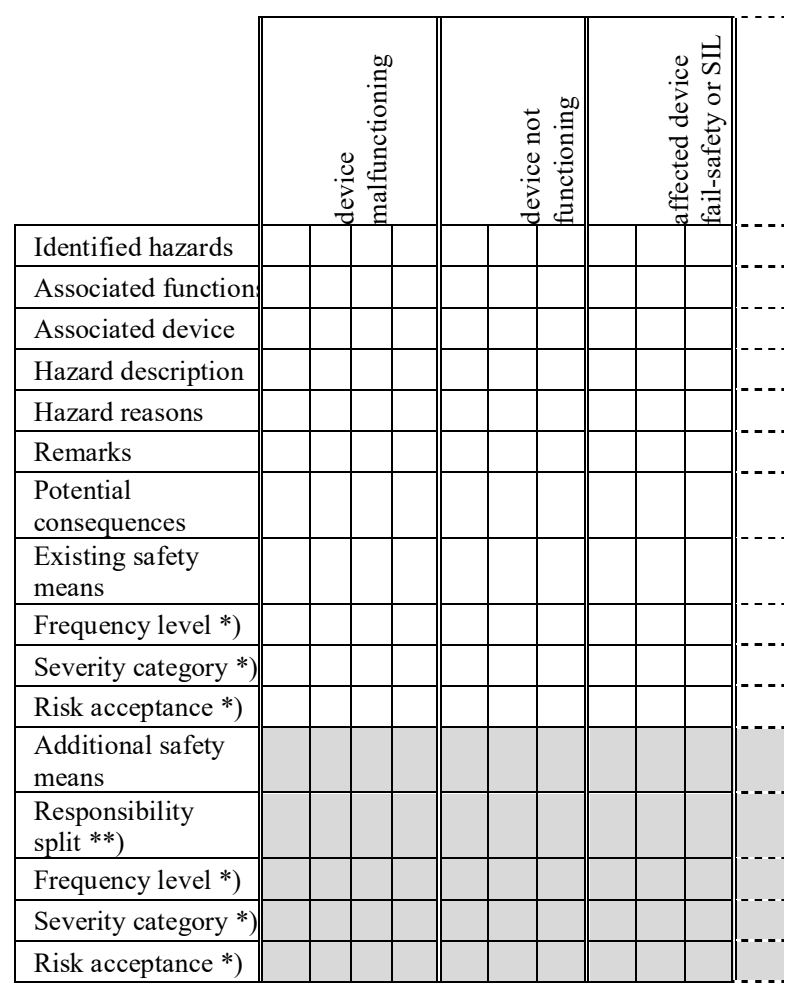

Fig. 2. Step by step approach to hazards (own elaboration): *) as defined in EN 50126 [6],

**) as defined in regulation 2013/402 [3].

\subsection{Complementary security aspects (T4 and T9)}

Moreover it is a must to ensure security especially in relation to prohibiting unauthorised access and protecting all critical places [T4] like control rooms, interlocking rooms, technical compartments, cabinets, etc. They have to be protected not only against vandalism and usual crime (against theft) but also against intentional fire ignitions and terrorist attacks which can result with fire.

Also rules defining split of staff responsibilities and procedures dedicated for preventing panic [T9] have to be defined, known and used.

\subsection{Extended hazard log with sensitivity verification for network running capability assessment}

Complementary safety and security aspects show, that some activities are not connected with fire verification of individual EMUs and vehicles forming trains.

Fire relevant fact have to be considered e.g. that amount of electrified lines entering tunnels on the Polish network is growing significantly, some tunnels are old 
and their reconstruction is not foreseen, new and old tunnels are used in commercial operation by new Electrical Multiple Units and existing EMUs as well as other trains including cargo ones.

It is proposed to use extended hazard log for assessing running capability in case of fire in the Polish network scale. It can be done by defining network

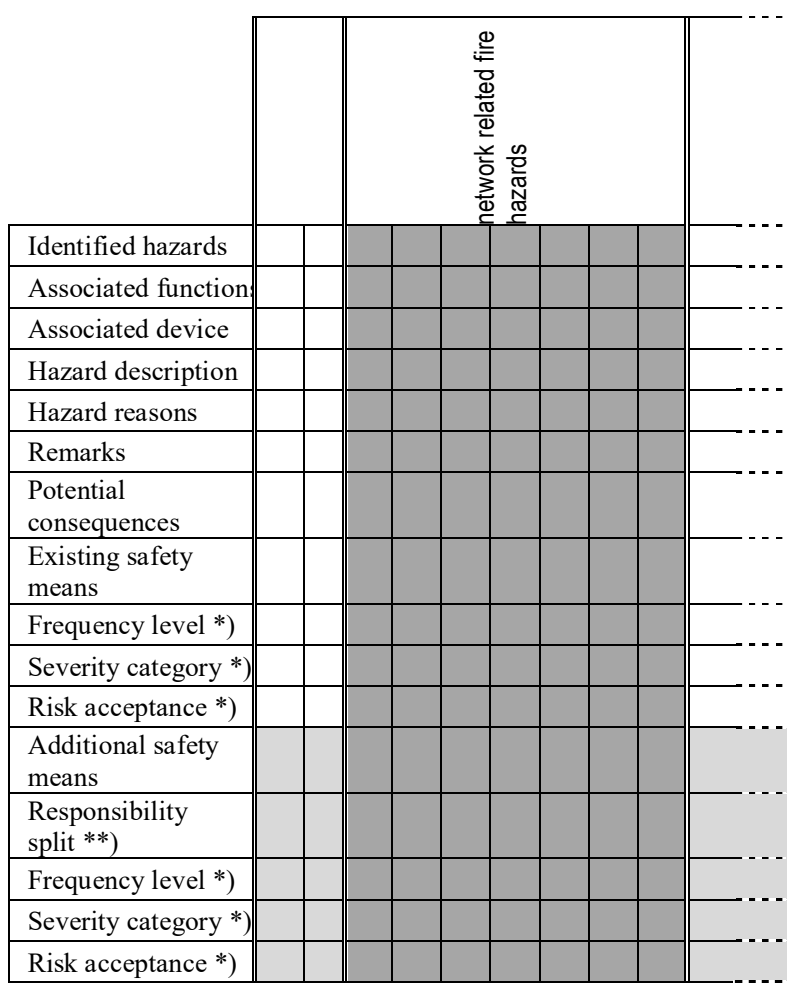

Fig. 3. Proposed network approach to tunnel fire hazards. (own elaboration)

related fire hazards, representing most sensitive combinations of trains and tunnels. It is proposed to take into account:

- existing old railway tunnel near Tunnel station on the railway line $\mathrm{nr} 8$ constructed in the nineteen century (1882-1884) used by passenger and freight trains operated by different railway undertakings on the line between Warsaw and Cracow,

- recently constructed (2008-2012) new railway tunnel already in operation, which is leading to railway station Warszawa - MPL Okęcie at the Warsaw airport used by passenger EMUs operated by two regional railway undertakings (Mazovian $\mathrm{KM}$ and Warsaw SKM),

- railway tunnel presently under construction over four tracks between Gdańsk Główny and Gdańsk Śródmieście, being constructed under full railway operation on long distance tracks between Warsaw and Gdańsk (Pendolino trains and freight trains with containers and with tank vehicles carrying flammable and explosive liquids going to the Gdańsk Seaport) and on local tracks between Gdańsk Śródmieście and Gdynia (old and new EMUs fulfilling and not fulfilling requirements related to running capability in case of fire.

It is proposed not only to consider different types of trains - new and existing operated since many years but also to take into account:

- presence of two trains in tunnel both in case of running on different trucks in opposite directions and in case of a train following another train which is also in a tunnel,

- pure passenger traffic with fire on board of one train as well as situations in which passenger train is in a tunnel together with freight container train with type 2 fire on board of the train.

Protection against fire of the tank vehicles carrying flammable and explosive liquids cannot be ensured such fire is considered to be EN 50533 type 3 fire. However disel fires which can take place in case of disel locomotives and Disel Multiple Units have to be taken into account. Lack of protection against fire in case of tank vehicles carrying flammable and explosive liquids does not mean that there is no need for minimising fire risk in case of dangerous goods - all trains and vehicles carrying dangerous goods have to be loaded, operated and unloaded in accordance with the COTIF (Convention concerning International Carriage by Rail) RID (Regulations concerning the International Carriage of Dangerous Goods by Rail) requirements.

Defining extended hazards for Polish case is therefore not only possible but also reasonable. The main representative hazards can be defined on the basis od tunnels and trains which are in regular operation over those tunnels. Such analyse would allow defining probably presently required additional safety means and the ways they would affect frequency levels and severity categories used for risk acceptance.

Such analyse should however be verified by sensitivity check. Defined additional safety means may ensure enough protection in case of scheduled traffic. Sensitivity analyse should verify whether they would ensure protection in case of reorganizations of traffic which takes place in case of operational disturbances. It is probable, that as a result some operational restrictions may be defined for resolving operational disturbances. For instance some old tunnels may be closed for some types of freight in normal operation and used for such purpose only in case of operational disturbances. Such use may be subject of individual decisions and may be forbidden to take place together with passenger traffic served by old trains or by all passenger trains.

\section{Conclusions}

It is reasonable and possible to conduct risk based analyse of safety aspects of the running with fire on the board of the EMU in the context of growing amount of the electrified lines entering tunnels in Poland. Such analyse may result with necessary technical safety measures and/or safety restrictions for operation. 


\section{References}

1. Directive 2008/57/EC of the European Parliament and of the Council of 17 June 2008 on the interoperability of the rail system within the Community (EU OJ L 191/1 of 18 July 2008) with further changes (which is to be superseded by Directive (EU) 797/2016)

2. Commission Regulation (EU) No $1303 / 2014$ of 18 November 2014 concerning the technical specification for interoperability relating to 'safety in railway tunnels' of the rail system of the European Union (EU OJ L 356/394 of 12 December 2014)

3. Commission Implementing Regulation (EU) No $402 / 2013$ of 30 April 2013 on the common safety method for risk evaluation and assessment and repealing Regulation (EC) No 352/2009 (EU OJ L $121 / 8$ of 3 May 2013) with changes

4. Office of Railway Transport President List of the relevant national technical rules and normative documents, which are being applied for achieving fulfilement of the essential requirements relevant for railway system interoperability, Office of Railway Transport, Warsaw 19 January 2017 (Lista Prezesa Urzędu Transportu Kolejowego w sprawie właściwych krajowych specyfikacji technicznych i dokumentów normalizacyjnych, których zastosowanie umożliwia spełnienie zasadniczych wymagań dotyczących interopera-cyjności systemu kolei, Urząd Transportu Kolejowego, Warszawa 19 stycznia 2017 r.)

5. EN 45545:2013 Railway applications - Fire protection on railway vehicles -Requirements for fire behaviour of materials and components - all parts (from EN 45545-1 to EN 45545-7)

6. EN 50126-1:1999 Railway Applications - The Specification and Demonstration of Reliability, Availability, Maintainability and Safety (RAMS) (which is to be superseded by FpprEN 50126-1:2017)

7. EN 50533:2012 Railway applications - Requirements for running capability in case of fire on board of rolling stock

8. J. Radziszewska-Wolińska, "Development of Requirements for Fire Protection of Rolling Stock in Poland and ITS Comparison with EN 45545", Railway Reports volume 57/2013 issue 160, Railway Research Institute, Warsaw 2013, ISSN 0552-2145

9. J. Radziszewska-Wolińska, "Revision Process of EN 45545”, Railway Reports volume 58/2014 issue 164, Railway Research Institute, Warsaw 2014, ISSN 0552-2145

10. M. Pawlik, "Bezpieczeństwo kolei w kontekście powiązań pomiędzy dyrektywami o bezpieczeństwie kolei i o interoperacyjności kolei, analiza z punktu widzenia zarządzania bezpieczeństwem" ("Railway safety in the context of relationships between railway interoperability directive and railway safety directive, analyse from the point of view of safety management"), Przegląd Komunikacyjny (Transport Review), 09/2016, ISSN 0033-22-32

11. M. Pawlik, "Safety, security and cybersecurity in railway operation", Safety and Reliability - Theory and Applications, 2017 Taylor \& Francis Group, London, ISBN 978-1-138-62937-0 